\title{
Meeting The Optical Talent Needs Of Industry In Europe
}

\section{H. Tiziani}

H. J. Tiziani, "Meeting The Optical Talent Needs Of Industry In Europe," Proc. SPIE 0978, 1988 Intl Conf on Education in Optics, (27 April 1989); doi: $10.1117 / 12.948592$

Event: 32nd Annual International Technical Symposium on Optical and Optoelectronic Applied Science and Engineering, 1988, San Diego, CA, United States 
MEETING THE OPTICAL TALENT NEEDS OF INDUSTRY IN EUROPE

H. J. Tiziani, Institute of Applied Optics

University of Stuttgart, Pfaffenwaldring 9, 7000 Stuttgart 80 , West Germany

\title{
$\underline{\text { ABSTRACT }}$
}

\begin{abstract}
The thematic "meeting the optical talent needs of industry in Europe" can be looked at from different points of view. In the present report the industrial activities and the education in optics are summarized.
\end{abstract}

My colleagues of the "Institut doptique" in Paris and the Imperial College in London will report on the curriculum in optics in Paris and London.

The emphasis is more on the model we use at the University of Stuttgart. It is a particular engineering curriculum forming engineers with a good optics background.

\section{INTRODUCTION}

Optics is frequently considered as a branch of physics. Modern optics, however, has been practised to a large extend also by persons trained in engineering, especially electrical and mechanical engineering. The mathematical preparation of electrical engineers seems especially favorable for topics of modern optics such as Fourier-and statistical optics, optical data as well as digital image processing, fiber optics and optical computer. 0ptical beams, resonator, modes and integrated optics, radar and phase measuring techniques are other topics appropriate to electronic engineers trained in microwave and antenna theory. At any rate there is a competition in modern optics, between physicists and engineers.

For the development of the optical instrumentation in Europe the optics industry in Germany and Switzerland played an important role. In this context Ernst Abbe at Carl Zeiss should be mentioned because he made important contributions to the development of optics in Europe. It is interesting to review the development of the German optics industry.

In 1846 Carl Zeiss in Jena was given the licence to produce and sell mechanical and optical instruments. He started in a small workshop. At first eye glasses, physical, chemical instruments and microscopes were produced. The design of lens systems for telescopes was known by Decartes, Huygens and Newton some 200 years ago and further developed by Fraunhofer. In 1866 Ernst Abbe was employed by Carl Zeiss where he improved the optical design techniques, invented the Abbe refractometer and the Abbe theory used today to describe the resolution in microscopy for instance.

After world war II, in 0ctober 4 th 1946 Zeiss opton optical works were founded, partly with coworker from Zeiss Jena, in Oberkochen in West Germany. In 1952 Schott in Mainz was established a leading glass producer in the world. Zeiss and Schott have today worldwide about 32000 employee.

Similar to Zeiss, the Leitz Company was initiated by a pioneer, Carl Kellner, in 1849 (kellner-ocular), and the first microscope was built in 1851. After his death in 1855 the small workshop was taken over by his chief engineer Friedrich Belthle, and in 1865 Ernst Leitz started working and became a partner of Belthle. In 1921 the Wild Company in Heerbrugg was founded by Heinrich Wild supported J. Schmidheiny and R. Helbling. After the merger of Wild-Leitz the Company had more than 8000 collaborators. This merger led to another stronghold of instrumental optics in Europe. Recently Kern Aarau joined the Wild-Leitz company. There are a number of other smaller companies in instrumental optics in West Germany such as Rodenstock (producing mainly eye glasses), Schneider, Kodak, Agfa and Sick (founded by the pioneer E. Sick 1946). In addition there are: Angenieux, Matra, Sopelem in France, Barr \& Straud, Ferranti, Pilkington in Great Britain with strong instrumental optics participation on the European market.

The optical instrumentation manufacturers were very much challenged by the strong competition from Japan. Today very few cameras (Leicas) are manufactured by European companies.

After the introduction of the laser in 1960 and solide state detectors and the computer age leading to a very powerful and efficient analysis of the information, optics is applied in different fields such as in medicine, in robotics and analytics. Radar and doppler shift 
techniques are also frequently used. Interferometry as well as contactless measurement with digital image processing are today and will in future be even more frequently used. Spectrum analysis is becoming more important to measure environmental disturbances and pollution. This means that the formation of the students needs to be adapted. An engineer in the optics field should have a sound background in applied optics; some knowledge in informatics, electronics and precision mechanics could be useful. Today even large companies like Philips, Siemens, Matra and Thomson have large groups in the fields of optics, sensorics and optronics.

Research sponsorship at universities depends on what kind of research is done. Government funding is very often directed into heavily favored areas such as advanced computer science, space projects, biotechnology or composite materials. Furthermore basic research is more difficult to be financed by industry. However there is an increase in cooporation between industry and universities, but industry is reluctant to finance fundamental scientific issues. They are primarily supporting technologies leading to quick commercial results. Collaboration with industry helps University and Industry at the same time. The research can be adapted to the need of the Industry. However some freedom for basic research at the university should remain.

A reasonable compromise is required which applies also to the publication of the work carried out with industrial support. Furthermore industrial contact is useful to get advise on new fields to be considered for the education. In addition some smaller projects can be carried out by undergraduate students in collaboration with the industry. It gives the students an idea for industrial needs and a feeling as being indicated for the industrial thinking and improves the collaboration with industry.

\section{EDUCATION IN OPTICS IN EUROPE}

There are different research centers in the optics field in Europe, offering some specialisations in optics. They are in Besançon, Delft, Florence, London, Paris, Madrid, Neuchatel, Berlin, Erlangen, Stuttgart and Stockholm to mention only a few. My colleagues Imbert and Smith will discuss the aim as well as the curriculum at the "Institut d"optique" in Paris and the Imperial College in London (offering a special degree of the imperial college in optics as well as a MSC). Fortunately I was able to obtain a BS from the Institut doptique in Paris after my BS in mechanical Engineering and a DIC and PhD (with H. H. Hopkins) from the Imperial college.

There is a basic difference in the system. In Paris you are trained as an engineer in optics whereas at the Imperial college you start with a BS in Physics and specialize in optics (DIC, MSC).

The main optics activities at universities in West Germany are in Berlin, Erlangen, Essen, Hannover, Munich and Stuttgart and in East Germany in Berlin, Jena and Illmenau. Mostly some specialized lectures are added to the physics curriculum with the real specialization in optics during the diploma work. You can therefore not get an optics degree or an MSc in Optics in West Germany or Switzerland, but rather a degree in Physics or engineering with some specialization in optics. There is not a strong emphasis on instrumental optics in the physics curriculum.

There are some specializations such as lens design in Berlin, optical metrology in Stuttgart, optical information processing, optical computer in Erlangen.

Forthermore there are different other levels of education in optics not directly related ta universities. Some additional training is also offered by the optical industry especially in optical design.

\section{APPLIED OPTICS CURRICULUM AT THE UNIVERSITY OF STUTTGART}

The optics education in Stuttgart is somewhat different to "what is offered usually". The Institute of "Technical 0ptics" was founded over 25 years ago and Prof. Schulze was the first director of the Institute. Applied optics is a track of the curriculum of mechanical engineering or precision mechanics which is unusual but seems to be appropriate to cover the need of the industry. In addition students interested in optics from the physics or electronical or physical engineering background attend some of the lectures given in optics.

For the curriculum of mechanical engineering in Stuttgart table 1 indicates some requirements for the engineering diploma. The student, having passed all the examinations of the first part of the studies selects one out of seven branches for the second part. Each branch 
consists of 6 lecture courses not coinciding with lectures of the main tracks to be chosen. For a specilization in optics the student can select optics as one of the two main tracks. Furthermore he can choose some appropriate optics lectures only and obtain credits for it. However if one of the two main tracks in the second part of the study is chosen to be optics, the student has the choice to select out of 27 lecture hours a week, indicated in table 2, at least 14. The lecture course is complemented by exercises and laboratory work as indicated in table 3, where some of the experiments to be carried out are indicated.

The preparation for further activities in industry is well served by introducing the students into project work. In our curriculum with two main tracks the student in fields of the main tracks selects projects as indicated in table 1. A few project propositions are summarized below. A small together with two large projects taking several weeks each and a diploma work taking a few months are needed to be chosen in the fields of the main tracks. In these projects usually problems close to the industrial needs are usually solved partly together with industrial collaboration. It should also be mentioned that 26 weeks of practical work in industry need to be accomplished in the first part of the study bringing the student into contact with industrial environment.

In addition to lecture courses the students can select a project in optics as diploma work for the physics curriculum or as a semester work for electronic engineering. With such possibilities the interdisciplinary aspect of future industrial activities is emphasized. The experiences we gained so far are very positive.

The curriculum in engineering in Stuttgart boosts the interdisciplinary aspect of education. In a system approach very often knowledge in electronics, precision machanics, optics and informatics needs to be combined as indicated in fig. 1.

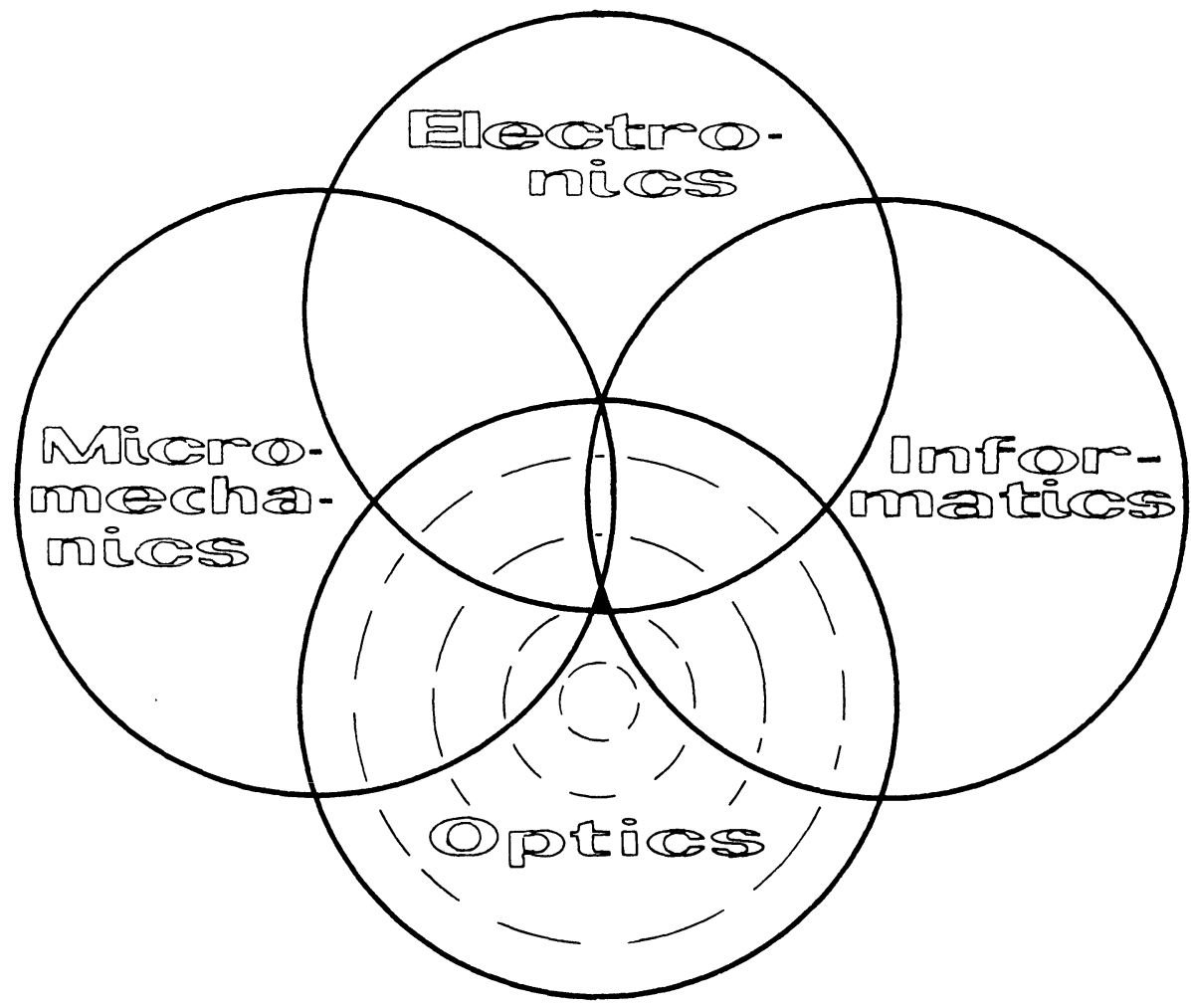

Figure 1 
TABLE 1

\section{CURRICULUM FOR THE ENGINEERING DEGRE (SECOND PART)}<smiles>C1CCCCC1</smiles>

\section{BRANCHES}

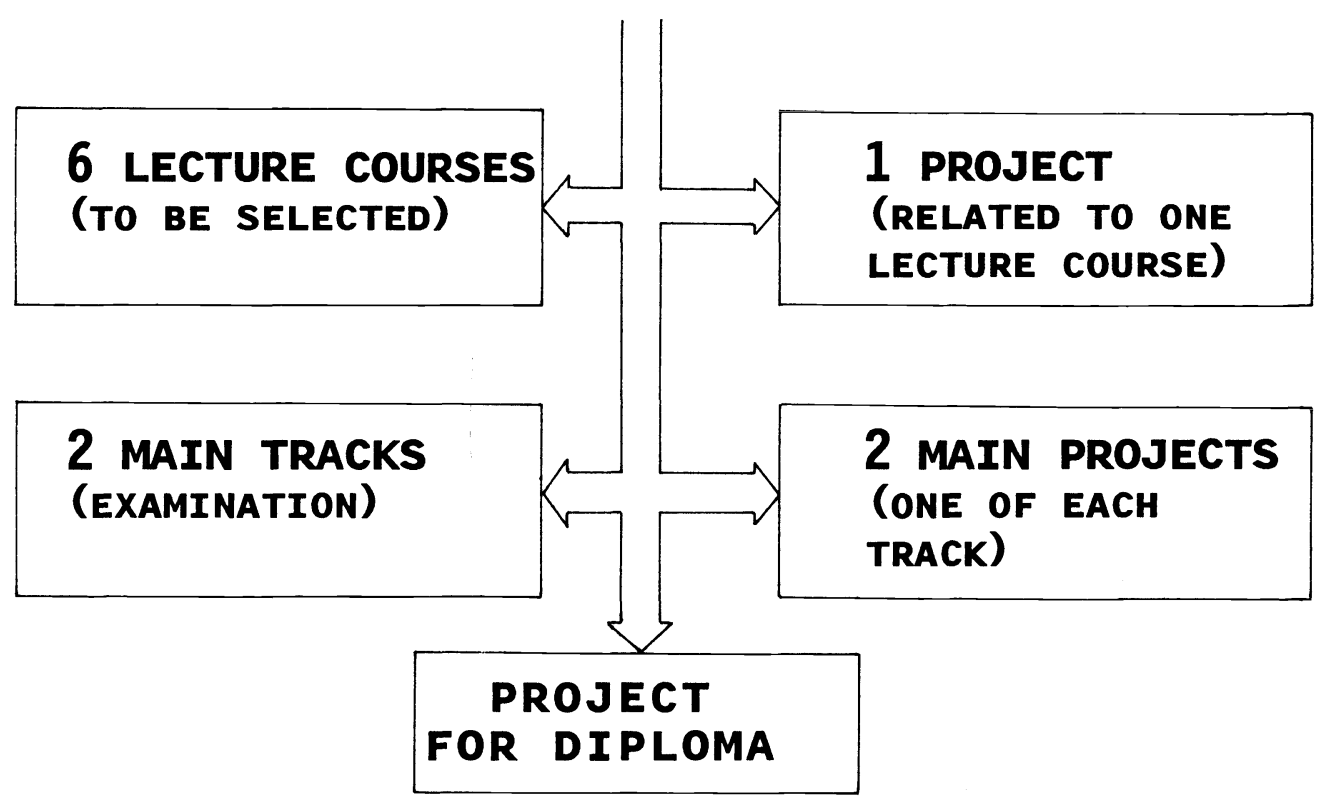

Table 2: LECTURE COURSES AT THE INSTITUTE OF TECHNICAL OPTICS

\begin{tabular}{|c|c|c|c|}
\hline & $\begin{array}{l}\text { weekly r } \\
\text { lecture }\end{array}$ & $\begin{array}{l}\text { ours/semes } \\
\text { exercise }\end{array}$ & $\begin{array}{l}\text { ter } \\
\text { comments }\end{array}$ \\
\hline $\begin{array}{l}\text { Fundamentals of } \\
\text { Technical optics } \\
\text { Optical metrology } \\
\text { Optical information processing } \\
\text { incl. digital image processing } \\
\text { Technical photography } \\
\text { Holography, laser and } \\
\text { Fourier optics } \\
\text { Optics of thin films, surfaces } \\
\text { and crystals } \\
\text { Instrumental optics, } \\
\text { Optical components } \\
\text { Geometrical optics and } \\
\text { lens design and } \\
\text { System analysis }\end{array}$ & $\begin{array}{l}2 \\
2\end{array}$ & $\begin{array}{l}2 \\
2 \\
2\end{array}$ & $\begin{array}{l}\text { recommended } \\
\text { for } \\
\text { optics track }\end{array}$ \\
\hline
\end{tabular}


Table 3: EXPERIMENTS IN THE OPTICS LABORATORY

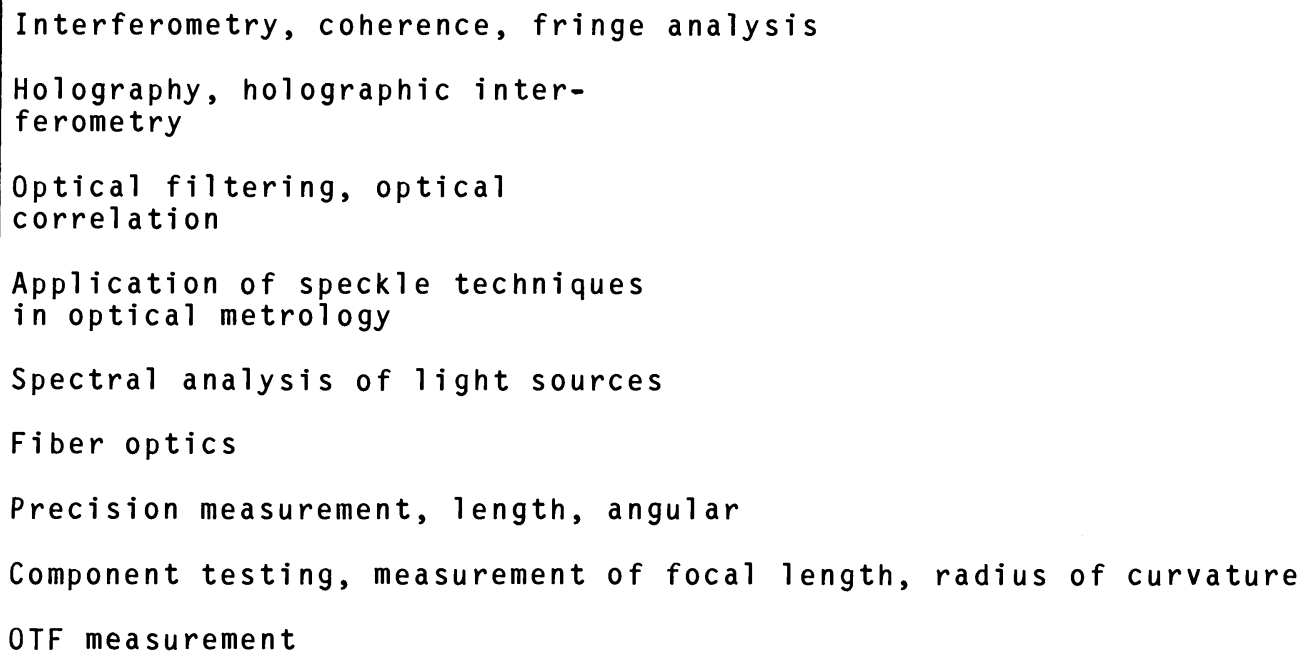

\section{PROJECTS FOR STUDENTS}

We consider project work as very important. Some of the recently selected projects are summarized.

- There are many projects in connection with instrumental optics and analysis of critical components

- Vibration analysis with Laser-Doppler vibrometer

- Practical comparison of different methods to measure microroughness

- Representation of 3-D-topography of scanned objects

- Interferometric analysis of non-rotational aspherical surfaces under industrial environment

- Automatic fringe analysis in holographic interferometry

- 2 techniques to be applied for surface topography

- Construction of a speckle interferometer with automatic fringe analysis

- Investigation of aberrations of holographic optical elements

- On-line measuring of the absorption and losses of optical fibers in production

- Study of the influence of temperature to the image quality and OTF

- Study of thin film storage material for holographic interferometry

- Investigation of photorefractive crystals for incoherent/ coherent conversion for real time optical correlation

- Integral roughness measurements using a speckle contrast method, determination of the parameters

- Theorie of photothermal interferometry

- Experimental investigation of photothermal interferometry for subsurface material defect analysis

- Waferinspection with photothermal interferometry

- Construction of an apparatus based on a new principle to measure surface roughness

- Application of holography for 3-D-contour 1 ines and interaction with CAD and CIM

- Phase conjugation with optically rough surfaces

- Development of a confocal microscope for the application in microelectronics

- 3-D-shape analysis with digital image processing

- Combination of 2- and 3-D image processing 


\section{SOME REMARKS TO THE LECTURE COURSES}

As far as the lecture courses for undergraduates. in Stuttgart are concerned there are basic lectures on fundamentals of technical optics including Geometrical - as well as physical optics, aberrations and photometry, radiometry and some instrumental optics. In optical metrology, classical and modern techniques for surface, length, shape and angular measurements of optical and technical components are discussed. Fringe analysis in interferometry and for moirétechniques are based on statical and dynamical methods.

In optical information processing Fourier optics, optical filtering and correlation for form and shape analysis, holography, holographic interferometry, speckle techniques, image formation in coherent and incoherent light as well as optical fibers, digital image processing are introduced. Furthermore the laser, coherence, polarization and wave theory, thin film and optical surfaces and crystals are treated.

In optical design the emphasis is on the system analysis as well as on system design and not so much on how to use computer programs.

In addition, there are lectures on the application of the laser for machining at the institute - "laser applications for machining".

\section{CONCLUSION}

The main emphasis in this presentation of the education in optics related to industrial needs is based on our stuttgart-model. From the requirements of the industry together with the experience gained from collaboration with the industry also by working on industrial projects the curriculum in optics with a sound background information turned out to be well accepted and seems to be successful. Although the fields and lecture courses are adapted to the need, instrumental optics is still kept as a basis for optical engineering. 